\title{
The Influence of Legal Proceedings on French General Practice: A Qualitative Study
}

\author{
Aurélia Nachbauer 1 , Humbert de Fréminville ${ }^{1,2^{*}}$ \\ ${ }^{1}$ General Practitioner Department, University of Lyon 1, Lyon, France \\ 2Laboratoire "Santé, Individu, Société", EAM 4128, Faculté de Médecine Laënnec 7-11 rue Guillaume \\ Paradin, Lyon, France \\ Email: aurelia.nachbauer@gmail.com, ${ }^{*}$ humbert.de-freminville@univ-lyon1.fr
}

Received 9 April 2014; revised 13 May 2014; accepted 20 May 2014

Copyright (C) 2014 by authors and Scientific Research Publishing Inc.

This work is licensed under the Creative Commons Attribution International License (CC BY).

http://creativecommons.org/licenses/by/4.0/

\begin{abstract}
Legal proceedings are becoming increasingly common in our society and especially in medicine. This raises the question as to whether General Practitioners (GPs) are concerned by this phenomenon. This study explores the impact of proceedings on the feelings and behaviors of different doctors. A qualitative semi-structured interview with 13 French GPs based on grounded theory was performed. A thematic analysis with major themes was then performed. This survey shows that lawsuits have little impact on the daily practice of GPs. Defensive medicine is practiced in certain specific situations: the treatment given, a patient known or perceived to be litigious. GPs attach importance to information and communicating to the patient. The primary concern of GPs remains their patients. They are not subject to daily anxiety over the risk of lawsuits.
\end{abstract}

\section{Keywords}

Consultation, Managed Care, Risk Assessment, Doctor-Patient Relationship, Primary Care, Medical Errors

\section{Introduction}

Legal proceedings are becoming increasingly common in our society and especially in medicine. The last twenty years have seen that more and more patients take out lawsuits when dissatisfied with their managed care.

This legal aspect of medicine has become an inherent part of initial medical training. Throughout their training, students are warned against the risk of litigation and are taught how to protect themselves on a daily basis (file traceability, official recommendations, and risk assessment). The question that we seek to answer here is to ${ }^{*}$ Corresponding author. 
determine whether litigation has an impact on the practice of family doctors at the end of their medical training. The latter mainly takes place in hospitals where the risk of legal proceedings is ever-present. Studies have shown the emergence of defensive medicine in general practice [1] in the United Kingdom [2], the United States of America [3], Australia [4] [5] and New Zealand [6]. Defensive medicine can be defined as the practice of ordering medical tests, procedures, or consultations of doubtful clinical value in order to protect the prescribing physician from malpractice suits (Merriam Webster Dictionary).

In France, two quantitative studies published in 2006 presented similar results [7] [8]: General Practitioner (GPs) have changed their practices due to the fear of possible prosecution. They increased their requirements for supplementary examinations, the use of specialist advice, and improved the information provided to patients.

The main assumption is that legal proceedings would tend to divert the physician away from their primary concern, the patient, to focus on their own protection against possible lawsuits. This includes time-consuming decision-making that requires them to leave a written trace of the options taken. The consequences are that less time is spent on the patients themselves. It is assumed that it is likely to introduce insidious fear into daily practice, thereby paralyzing the capacity to act. But it also seems likely that it contributes to improving practices by requiring doctors to keep recommendations up to date. It obliges them to stand down from their pedestal of omnipotence and improve the information given to patients in view to shared decision-making.

It is assumed that legal proceedings have more impact on the practice of young GPs. They are more sensitive and attach greater importance to them since they are a facet of their medical training from the beginning. Thus they integrate this risk in their practice, unlike older generations for whom it is more abstract. Legal proceedings may have less impact in suburban and rural areas, due to a less litigious, consumer-oriented and mobile patient base. The patients of suburban and rural doctors are more attached and dependent on the latter in comparison to patients of urban areas. This is because the narrower offer of care does not allow doctors to protect themselves every time they have a doubt by transferring responsibility. Consequently, this reduces the aspect of legal proceedings in their daily practice.

This study explores the feelings and behaviors of various GPs with joint collection, coding and analysis of incidents (i.e. occurrences).

\section{Materials and Methods}

\subsection{Participant Selection}

The size of the sample was fixed at 18 GPs installed in southeast France (Rhône-Alpes area), divided into three groups of six physicians by type of practice (urban, suburban and rural) in each subgroup, with three doctors having practiced for less than ten years and three having practiced for over ten years. It was planned to stop sampling once data saturation was reached. GPs were recruited via the websites of the National Council of the College of Physicians and yellow pages if necessary, according to the Public Health Code (R 4127).

\subsubsection{Inclusion Criteria}

The inclusion criteria were being a GP, having a practice in the city of Lyon for urban areas, being no more than thirty minutes away by car from the investigator's home for the semi-rural GPs, and an hour away for rural GPs. 46 doctors were called, 9 refused to participate (7 urban, 2 rural and no semi-rural).

\subsubsection{Exclusion Criteria}

The exclusion criteria were a year in hospital, clinic, a specific orientation (sports medicine, gerontology, allergy, etc.), belonging to a public or private structure, and having a direct link with the investigator. 2 doctors were excluded because general medicine was not their main occupation (1 was an osteopath, 1 was a member of a union). 22 were excluded as the quota of physicians practicing for less than ten years had been reached.

\subsubsection{Setting}

11 doctors were interviewed at their office, 2 doctors were interviewed outside their office (one at his home, one at his retirement home).

\subsubsection{Ethical Committee}

The survey did not require approval from an ethical committee (L 1121-1 of the Public Health Code) and it 
conformed to French professional practice (R 4127 of the Public Health Code).

\subsection{The Method}

\subsubsection{Personal Characteristics}

The first researcher, a female Medical Doctor (MD) fellow, conducted semi-structured interviews with GPs; the second researcher, a male $\mathrm{MD}-\mathrm{PhD}$, performed data triangulation. Both researchers attended training courses on qualitative methods and design beforehand. The interview grid was developed with the help of a teacher qualified in qualitative studies on general medicine. The investigator tested the grid on a pilot sample with 4 general practitioners without first broaching the subject with them (to maintain neutrality and spontaneity). Some questions were then reformulated, simplified and made more open. A reminder of the definition of legal proceedings was added to the preamble of the interview. This test also allowed the interviewer to practice the interview technique and subsequently attempt to correct flaws in the study.

\subsubsection{Relationship with Participants and Study Design}

The methodological orientation was the grounded theory (GLASER and STRAUSS, 1967). The interviews were conducted from April to May 2012, after making an appointment by telephone and describing the subject of the research. Each physician was contacted by telephone, by order of selection, with care taken to ensure a mix of gender, time and place of practice, and to present the study and obtain their agreement to participate. They were recorded by tape recorder with the consent of the respondents.

\subsubsection{Data Analysis}

The investigator transcribed the interviews manually, accurately and anonymously to create 13 verbatim records. The transcriptions were then analyzed by two data coders and matched against a classification of incidents or occurrences in descending order of frequency. The occurrences led to a thematic analysis with major themes. Data saturation was reached with 13 GP interviews. This could be explained by the professional sample which was focused on their current practice. Participants did not provide feedback on the findings.

\subsubsection{The Grid}

After three questions on the characteristics of the physicians surveyed, the grid consisted of four main issues with reminders for each of them if necessary. The first question was very open to encourage the doctor to speak on the subject without any guidance, the second focused directly on the impact of legal proceedings on medical practice, the third explored the respondent's experience of facing conflicts with patients and, finally, the fourth sought to determine differences of impact depending on the physician's characteristics (essentially age and place of practice).

\section{Results}

\subsection{Population (Table 1)}

13 GPs were interviewed with a breakdown according to the inclusion criteria as follows: 4 doctors of which 1 had been practicing for less than 10 years (urban), 5 doctors of which 2 had been practicing for less than 10 years (suburban), 4 doctors of which 1 had been practicing for less than 10 years (rural).

\subsection{Thematic Analysis (Figure 1)}

\subsubsection{Prevalence and Integration of Legal Proceedings in Daily Practice}

Legal proceedings are an established and inevitable risk, but not necessarily a major concern for the majority of GPs. They recognized it as a risk inherent in current practice (Dr B: "I consider them to be parasitical but not as an additional stress", Dr C: "I know that they will increase"), but one that did not generate specific anxiety on a daily basis. It has not changed their practices. Two doctors also described legal proceedings as inevitable (Dr K.: "Even when you do your work well, you can’t escape exposure”). This finding applies to young doctors whose medical education has incorporated the notion of medical-legal risk from the beginning, so they are ready to face it. It also applies to older physicians who have recognized a growing prevalence in recent years, although for them it still remains a rather abstract notion. One of the respondents who had been quite upset by his legal 
Table 1. Population-13 GPs were interviewedfrom April to May 2012 in southeast France.

\begin{tabular}{cccccc}
\hline GP & Gender & Age & Location & $\begin{array}{c}\text { Beginning } \\
\text { of practice (Year) }\end{array}$ & Office individual/Team \\
\hline Dr A & M & 54 & Suburban & 26 & Individual \\
Dr B & M & 51 & Rural & 21 & Individual \\
Dr C & M & 41 & Urban & 16 & Team \\
Dr D & M & 53 & Rural & 26 & Individual \\
Dr E & M & 44 & Suburban & 15 & Team \\
Dr F & M & 39 & Rural & 12 & Individual \\
Dr G & M & 31 & Suburban & 4 & Team \\
Dr H & F & 61 & Suburban & 65 & Team \\
Dr I & M & 34 & Urban & 26 & Individual \\
Dr J & M & 60 & Rural & 2 & Substitute GP \\
Dr K & F & 32 & Urban & 5 & Team \\
Dr L & M & 34 & Urban & 34 & Team \\
Dr M & F & 59 & & & \\
\hline
\end{tabular}

experiences had done little to change his practice, apart from the way he kept his records.

Many perceived prosecution as a threat to their practice and many doctors believe that the fear of being brought to trial is greater than the actual risk (Dr A: "It's a real poison, but more in the mind than in fact").

\subsubsection{Communication and Information for the Patient}

The GPs attached importance to patient communication and information, which are causes of legal proceedings if absent (Dr F.: "For me, litigation is above all linked to the fact that the communication between care-givers and patients isn't always good"). Information applies to both diagnostics and the therapy proposed, but also to the balance between the benefit and risk of any intervention. According to them, it helps to protect GPs from prosecution.7 GPs said that access to information by patients has developed considerably due to the Internet (Dr F.: "Everyone has access to medical information via the Internet"). This raises the problem of an overload of information not always understandable to the layman. It is therefore the role of the physician to provide the necessary explanations. If information is misunderstood by the patient, it can lead to prosecution. Extensive and incomprehensible information provided by certain specialists (including surgeons), due to the obligation to obtain informed consent, was reported by GPs (Dr B: "The consent is given, but awareness is lacking”. The doctors interviewed were conscious of an aberration due to the fear of prosecution. Many doctors stressed the importance of taking time to inform patients. Although informing patients is time-consuming. Taking time during consultation is necessary to ensure quality and avoid misunderstandings (Dr H: "I have to say that I talk a lot with my patients. I don't just see them in two seconds. That helps a great deal.”).

Another repeatedly stated view was that legal proceedings have put an end to paternalistic attitudes and the omnipotence of doctors (Dr K: “The doctor isn’t all powerful.”). This is particularly due to the requirement to inform patients, which has been obligatory since 2002. Some also said that changes in medical training were responsible.

Some of the respondents declared that it is necessary to take the time to listen, talk and explain if medical errors, adverse events or conflicts with a patient occur. According to them, they did not hesitate to admit their mistake and explain the circumstances. Patients are quite able and willing to understand that doctors are not infallible (Dr A: "Patients know that we can be wrong. However, they don't want to be taken for idiots"). This can usually settle situations amicably and relieve the doctor.

\subsubsection{Doctor-Patient Relationship}

For most doctors the patient's interest comes first in their decisions (Dr G: "They are always taken in the interest of the patient; curing them comes first."). They care about their patients before worrying about the legal side even if this means taking legal risks in ignoring expert advice or theory. Some of the GPs admitted that they mostly ask for additional tests or expert advice on behalf of the patient. But sometimes they do this to protect 


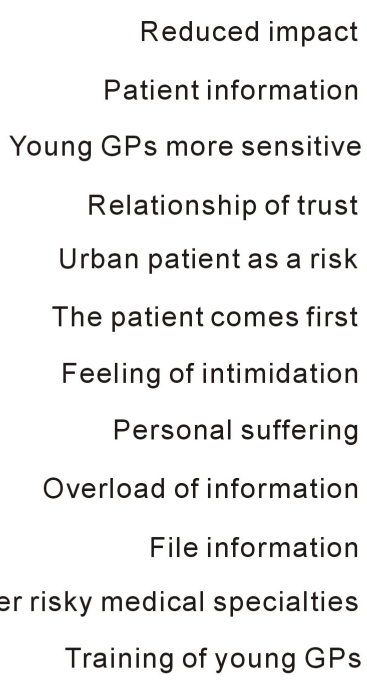

Take time to give information to the patient

On-guard regarding prosecution

Being experienced is protection

Standard objectie

Inproverishment of family practice

Family practice is a risky profession

Proceedings part of pratice like in USA

Better feeling

GPs excluded

GPs Challenged

Stress

End of paternalism

Caution about medical certificates

GP interrupts profession

Rural activity more risky

Patient's relatives

Patient gains rocognition

Casualty

Burn out

Human mistake

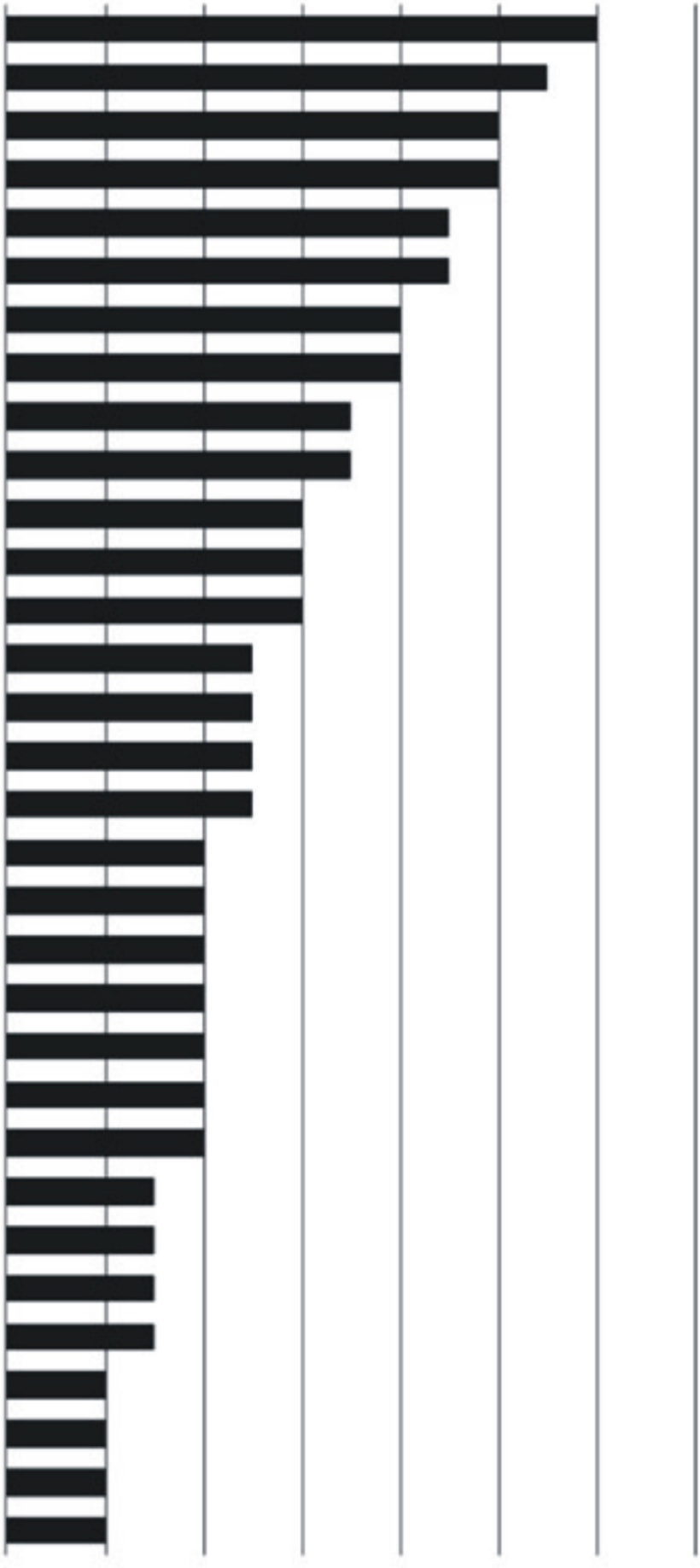

0 2

6

8

10

12

14

Number of GPs

Figure 1. Thematic analysis from a classification of occurrences in descending order of frequency (qualitative method, semi-structured individual interviews of $13 \mathrm{GPs})$.

themselves when patients are perceived as litigious, are unknown to them or in custody. Also, some physicians had stopped administering care for the good of the patient rather than due to legal risks. 


\subsubsection{Personal Suffering}

The interviews highlighted that possible proceedings are seen by many GPs as very difficult and traumatic, both professionally and personally (Dr J. "It's often difficult to swallow.”). The words used were strong. Some GPs had considered giving up their profession or imagined sinking into depression. Others, who had experienced this kind of trouble or simply conflicts with patients, recounted their memories with bitterness. A notion that recurred several times was the doctor's feeling of injustice and misunderstanding when confronted by prosecution. Many doctors complained of judicial bias and no aid from insurance companies in the case of dispute (Dr I.: "The person from the insurance company supposed to be defending my colleague was making their case worse without understanding why.”).

\subsubsection{A Relationship Based on Trust}

According to a large majority of physicians, a trusting relationship between the doctor and patient is the main factor protecting against legal proceedings in primary care (Dr H.: "It's a relationship that protects us a little."). Indeed, they believe that knowing their patients and having a trusting relationship with them removes the legal aspect in case of conflict and it makes patients more forgiving and understanding. Thus doctors are aware of the greater risk of proceedings and are therefore more cautious with unknown patients. For some, the lack of experience of young doctors when starting their practice with their patients and families makes them more vulnerable to the risk of a lawsuit.

\subsubsection{Young Doctors and Their Elders}

The majority of doctors agreed that young GPs are more sensitive to legal proceedings than older ones (Dr H.: "We elder doctors have never received this training."). Two main reasons were given: their training now includes the aspect of lawsuits and their inexperience makes them more cautious with regard to potential error. However, many older doctors also explained that the training now given to young doctors has led them to keep a written record in the patient's file in order to protect themselves. The young doctors surveyed tended to think that their seniors are more affected by the impact of taking legal proceedings into account, because it is imposed on them retrospectively. The older physicians were unfamiliar with the risk and had to adapt. On the other hand, due to their longer careers the older physicians had already had problems of this kind and were sensitive to the issue.

\section{Discussion}

\subsection{Bias}

There is an inevitable selection bias since the subjects were not included in this study randomly but selected to obtain a diverse sample. However, in qualitative research, the goal is not the representativeness of the results but their adequacy.

There are also biases related to the interviews. Firstly, the acquisition of the data was triggered artificially by the interviews themselves [9]. Various methods were used to reduce this bias: the interviews were conducted in the natural environment of the respondents [10] (doctors' surgeries) and care was taken to create a climate of trust (face-to-face, empathy, recording the conversation rather than the questionnaire, descriptive questions at the beginning of the interview) [11]. Then, there was the subjectivity of the researcher who formulated open and neutral questions. Finally, there was the gap between what doctors said about their practices, the reality described and their potential oversights [12]. The researcher tried to adopt a tone and attitude that was as neutral as possible and refrained from making comments or giving feedback. Questions were sometimes reformulated to clarify ambiguities.

Bias due to data collection limitations: the time constraints of the respondents (from 11 to $30 \mathrm{~min}$.), although they had been informed of the expected duration of the interview; interruptions by external factors (phone, person), but these were rare and the doctors did not lose the thread of the ideas in play.

The last bias related to the analysis method is interpretation bias. Data saturation and triangulation were applied to guarantee the plausibility of our interpretative assertions. Nevertheless, the observational data were limited because most of the doctors behaved very neutrally, probably in keeping with their profession. Finally, there was the cultural proximity of the interviewer and interviewees. This was an advantage as it allowed the re- 
searcher to better understand the context of the respondents' environment. On the other hand, it is also a disadvantage because it creates familiar stereotypes, making it more difficult to stand back from the results.

\subsection{Validity}

The answer to the initial premise of this research was negative since we showed that the primary concern of doctors is above all the patient and not their own protection against potential lawsuits. One can imagine that the doctors were reluctant or embarrassed to admit the contrary, since putting the patient first is the founding principle of their profession (French public health code R 4127-1 to R 4127-55). However, their responses to the entire survey were consistent with this assertion, giving plausibility to this result and they were not reluctant to admit other changes in their practice taken to protect themselves.

Our qualitative study places the impact of legal proceedings in perspective in comparison to previous French and international studies (NASH, 2010) and (CUNNINGHAM, 2006). Indeed, defensive medicine seems to apply in particular to situations such as having to treat a patient in custody, a first-time patient or one who appears litigious. However, doctors complained that litigation leads to less diversity in practicing general medicine, arguing in favor of non-defensive medicine.

This study confirmed the importance that doctors attach importance to the development of patient information and communication, prior to and following a conflict. They sometimes complain about excess information that is incomprehensible to patients and which may create distrust of the medical profession.

Unlike other studies (STUDDERT, 2005) and (SUMMERTON, 2000), this study shows that French doctors do not intend to end their careers early or reduce their hours because of litigation. However, they perceive legal proceedings as a traumatic experience. The doctors interviewed said that the risk of being confronted by lawsuits was not a daily concern, especially as they felt protected by having built a trusting relationship with their patients, a factor highly specific to general medicine.

Also, this survey did not find any significant difference in impact between the young doctors and their older colleagues or between different contexts of practice. Finally, each doctor felt less affected than their colleagues. Only a few nuances were identified: young doctors are more careful in keeping medical records. Doctors in urban areas are less vocal about legal proceedings whereas doctors practicing in rural and semi-rural areas seem to have more privileged relationships with their patients, which affects them more in the case of litigation. Furthermore, their practices are more diversified and thus potentially more affected by the increased risk of legal proceedings, causing them to be more cautious.

\section{Conclusions}

Legal proceedings have now become part of general medical practice. This study provided a qualitative perspective of its impact. The primary concern of GPs remains their patients. They are not subject to anxiety generated by legal risks even if they perceive legal proceedings as a traumatic ordeal. They foster communication with the patient as part of a critical societal change and feel protected by the relationship of trust they build with the patient.

The defensive medicine described in previous studies in France and other countries is postulated only in situations that doctors perceive as potentially risky: on duty calls, first-time patients, difficult patients and procedural patients.

However, doctors tend to practice defensive medicine, by limiting their exposure to risk, although they deplore this situation. Further qualitative research could explore patients' opinions on themselves and on their GPs to increase plausibility. The same qualitative method, namely semi-structured individual interviews, could be used to study patients and doctors of different ages and areas of practice.

\section{Funding}

None.

\section{Ethical Approval}

This qualitative survey did not require approval by an ethical committee in France (L 1121-1 of French Public Health Code) and it conformed to French professional practice (R 4127 of the French Public Health Code). 


\section{Conflict of Interest}

None.

\section{Acknowledgements}

The French Family Physician Teaching College of Lyon, France (CLGE) for supporting this work.

\section{References}

[1] Studdert, D.M., Mello, M.M., Sage, W.M., Des Roches, C.M., Peugh, J., Zapert, K. and Brennan, T.A. (2005) Defensive Medicine among High-Risk Specialist Physicians in a Volatile Malpractice Environment. The Journal of the American Medical Association (JAMA), 293, 2609-2617. http://dx.doi.org/10.1001/jama.293.21.2609

[2] Summerton, N. (2000) Trends in Negative Defensive Medicine within General Practice. British Journal of General Practice, 50, 565-566.

[3] Kessler, D.P., Summerton, N. and Graham, J.R. (2006) Effects of the Medical Liability System in Australia, the UK, and the USA. Lancet, 368, 240-246. http://dx.doi.org/10.1016/S0140-6736(06)69045-4

[4] Nash, L.M., Walton, M.M., Daly, M.G., Kelly, P.J., Walter, G, Van Ekert, E.H., Willcock, S.M. and Tennant, C.C. (2010) Perceived Practice Change in Australian Doctors as a Result of Medicolegal Concerns. Medical Journal, 193, 579-583.

[5] Nash, L.M., Walton, M.M., Daly, M.G., Johnson, M., Walter, G., Van Ekert, E., Willcock, S. and Tennant, C. (2009) GP's Concerns about Medicolegal Issues-How It Affects Their Practice. Australian Family Physician, 38, 66-70.

[6] Cunningham, W. and Dovey, S. (2006) Defensive Changes in Medical Practice and the Complaints Process: A Qualitative Study of New Zealand Doctors. New Zealand Medical Journal, 119, U2283.

[7] Fasquelle, N. and Faict, T. (2006) La judiciarisation de la médecine générale et la pratique médicale. Thèse d'exercice de Médecine, Faculté de Médecine de Clermont Ferrand I, Clermont Ferrand.

[8] Bourcier, J. and Bismuth, S. (2006) La judiciarisation et l'exercice de la médecine générale en 2005: Réflexions à propos d'une enquête auprès de 136 médecins généralistes de la région Midi-Pyrénées. Thèse d'exercice de Médecine. Faculté des sciences médicales Rangueil, Toulouse.

[9] Gubrium, J.F. and Holstein, J.A. (1997) The New Language of Qualitative Method. Oxford University Press, New York.

[10] Briggs, C.L. (1986) Learning How to Ask: A Socio-Linguistic Appraisal of the Role of the Interview in Social Science Research. Cambridge University Press, Cambridge, London, New York. http://dx.doi.org/10.1017/CBO9781139165990

[11] Spradley, J. (1979) The Ethnographic Interview. Holt Rinehart \& Winston, New York.

[12] Silverman, D. (2010) Doing Qualitative Research: A Practical Handbook. 3rd Edition, Sage Publications, London. 